\title{
Uncertain with a chance of showers
}

\author{
Global hydroclimate and atmospheric dynamics are tethered, and so is their future uncertainty. Despite this, \\ scientists are increasingly able to identify climate change signals in noisy hydroclimate observations, aided by a \\ growing line-up of climate model experiments and an ever-extending observational record.
}

A prominent feature of global hydroclimate is the intertropical convergence zone (ITCZ), a rain band that snakes around the Earth like a wavy belt (Fig. 1). While climate change's impacts on the hydrological cycle are complex, increased ITCZ rainfall is expected, stemming from the idea that a warmer atmosphere can hold more water vapour. The atmospheric circulation, with air rising at the equator and sinking in the arid subtropics, interacts with increased moisture to reinforce these wet and dry patterns ${ }^{1,2}$. These changes are commonly referred to as the wet-get-wetter and dry-get-drier mechanism, and are reliable at large scales, but land-atmosphere interactions and regional circulation patterns drive local exceptions ${ }^{3}$.

The ITCZ tracks the warmer hemisphere in an annual north-south migration, helping transport excess heat away from the summer hemisphere. This causes seasonal cycles causing wet and dry periods in monsoon regions and elsewhere. This seasonal migration is expected to be delayed under climate change, notably over the Sahel ${ }^{4,5}$, and recent work has shed light on the why ${ }^{6}$. During the transition season, the autumn hemisphere contains additional heat with climate change, leading to a more lethargic ITCZ that transitions later into the spring hemisphere. These changes help explain delays in global monsoon onset and rainfall in agriculturally-dependent wet seasons.

Understanding the ITCZ phase delay is important, but whether it is already measurable in observations is an open question. That's because tropical precipitation is highly variable, and global observations are most reliable during the satellite era (1979 onwards), which can be too short to capture long-term signals. In this issue, an Article by Fengfei Song and co-authors finds that an approximately 4-day seasonal delay of tropical precipitation is measurable over Northern Hemisphere land as of 1979-2019. The researchers confirm this across eight gridded precipitation datasets and several climate model ensembles, and attribute it to anthropogenic warming.

Song and colleagues use Coupled Model Intercomparison Project Phase 6 (CMIP6) experiments to further quantify the competing effects of aerosols and greenhouse gases (GHGs). Anthropogenic aerosols enhance cloud formation and scatter sunlight, 'dimming' the climate and counteracting GHG-induced warming. This opposing effect partly offsets the seasonal delay in climate models ${ }^{7}$, but as aerosol emissions decrease in the future, their counteracting influence will likely weaken.

Changes to ITCZ migration timing are superimposed on other trends. The tropics and higher latitudes exhibit a two-way communication through large-scale waves in the atmosphere, called planetary or Rossby waves. Recent work has suggested that climate change will cause these waves to amplify in a way that increases the likelihood of concurrent heatwaves across important crop regions ${ }^{8}$, and summer weather may become more persistent ${ }^{9}$. Teleconnections associated with tropical rainfall and sea surface temperature variability, like El Niño and the MaddenJulian Oscillation, are also expected to change as a result, with amplified impacts on precipitation ${ }^{10-12}$.

Also in this issue, an Article by Karen McKinnon and colleagues explores how heatwaves in the US Southwest have changed. Using station data, gridded observational datasets and CMIP6 output, the researchers find that the hottest days in summer have become drier since the mid1900s. This may seem intuitive - more heat will likely lead to drier conditions in an already dry region - but it contrasts with the expectation that a warmer atmosphere will generally hold more water vapour.

This result highlights the need to consider regional atmospheric dynamics and land-atmosphere interactions together when inspecting how climate change affects local climate and precipitation patterns. These drier heatwaves could be a product of several things: more arid soil, decreased rainfall or circulation-driven moisture decreases. The researchers track changes in these sources and pinpoint soil moisture declines as the primary cause. This is in line with recent increases in heat-driven evapotranspiration ${ }^{13}$, though drylands can also exhibit offsetting feedbacks that enhance atmospheric moisture import ${ }^{14}$. McKinnon and colleagues also analyse how

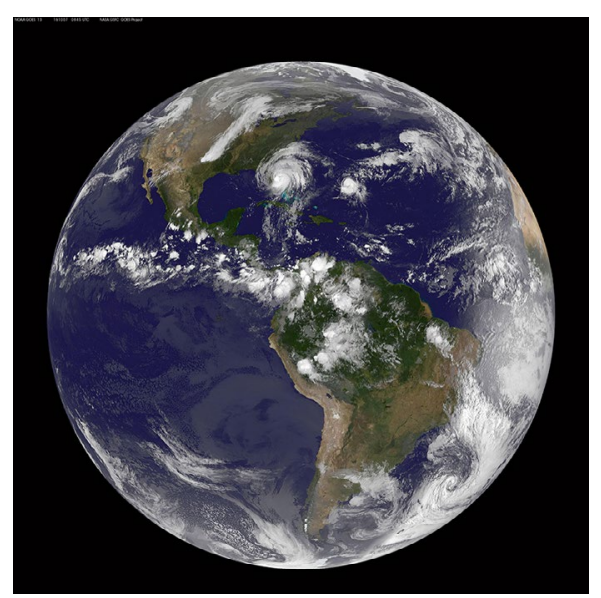

Fig. 1 | Satellite image from NOAA GOES-East satellite on 7 October 2016. The ITCZ is seen along the equator west of Central America. Credit: NOAA / Alamy Stock Photo.

hot days may evolve in CMIP6 projections, but uncertainties in soil moisture and precipitation change lead to inconclusive results.

Climate model disagreement in regional atmospheric dynamics guides some of the more intractable uncertainties in future hydroclimate. But as climate change continues on, so grows the observational record and climate model archive, and with them evidence that not only will climate change alter many aspects of the hydrological cycle, it has already started to.

Published online: 6 July 2021

https://doi.org/10.1038/s41558-021-01100-y

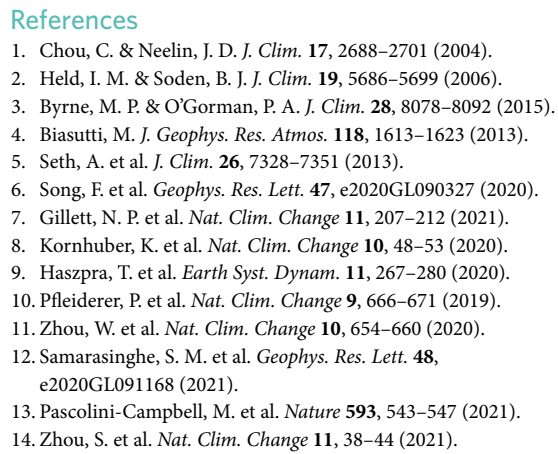

